\title{
The Study on Development and Countermeasures of Qingdao Sailing in Under the Background of "The 2018 SCO Summit"
}

\author{
Xiuying $\mathrm{Hu}^{1} \&$ Guanjun Wang ${ }^{2}$ \\ ${ }^{1}$ College of Physical Education, Qingdao University of Science and Technology, Qingdao, Shandong, China \\ Correspondence: Xiuying Hu. E-mail: xbsdhxy2003@163.com
}

Received: September 30, 2018

Accepted: October 25, 2018

Online Published: November 29, 2018

doi:10.5539/ass.v14n12p236

URL: https://doi.org/10.5539/ass.v14n12p236

\begin{abstract}
The SCO summit of Qingdao was an important diplomatic activity for China, and it was a global event.

General secretary Jinping Xi has given important instructions on the success of the SCO summit in Qingdao. He has hoped to sum up the useful experience of "having a good meeting and invigorating a city" carefully.

The historical experience has also proved once again that an important international conference brings great impetus and promotion effect to a city. Therefore, as the "SCO summit city", Qingdao is also the "Olympic sailing capital" and "ocean city".

With the continuous development of China's marine sports, sailing has gradually entered the horizon of people. However, China started late in sailing, and competitive sailing has only achieved relatively good results in recent years. It is developing competitive sailing boats. At the same time, the development of recreational sailing is also to be strengthened. The development of recreational sailing is in line with people's demands for exploration of the sea, recreation, and healthy life, so that the popularity of sailing has become a national sport that has strengthened both the north and the south of China. The interaction between the parties has also strengthened economic and cultural exchanges and cooperation between home and abroad. (Qing, 2018)

This article has analyzed the status quo of the development of leisure sailing in Qingdao. Its purpose was to analyze the problems of leisure sailing in the process of developing idle resources and lack of reserve forces, and proposed the corresponding solutions and suggestions. For example: rational using of resources to deal with seasonal changes; using of media channels to promote leisure Sailing; developing of reserve forces; sailing events for the masses; organizing community activities. At the same time, it has drawn same lessons from the development experience of foreign leisure sailing and selects suitable methods to cater for the development of leisure sailing in Qingdao.

This article has used the literature, expert interviews and questionnaires to explore the current status of the development of leisure sailing in order to promote the coordinated development of leisure sailing in Qingdao in the future with social, economic and cultural development.
\end{abstract}

Keywords: The 2018 SCO summit of Qingdao, leisure sailing, development status, countermeasures

\section{Preface}

The "Summit city" has become a beautiful new business card of Qingdao. Under this influence, the tourism industry has felt the "enthusiasm" brought by the summit firstly. After the SCO summit, the tourism environment, service facilities and reception level of Qingdao have been improved comprehensively. Qingdao was also more confident, has opened its arms to welcome visitors from all quarters, and presented the city's unique natural features and cultural charm.

Under the "summit effect", "he Dragon Boat Festival" was the first mini-holiday after the summit, has received 409.44 million tourists, growing up of 35.8 percent year-on-year. The summer travel was also booming. As of August 26, the Laoshan scenic area has received 140.7 million tourists, growing up 21.6 percent from the same period last year. The Qingdao international conference center has been talking about more than 50 projects within half a month after the summit and the schedule has been arranged to 2020 (Liu, 2018).

At the same time, Qingdao has won the "double champion" of China's most featured tourism city ranking and China's happiest city ranking according to the 17th ranking of global national (urban) competitiveness 
classification advantages in 2018.

Qingdao has been the main sailing venue for the 2008 Beijing Olympic Games. As the "summit city", as the "sailing capital", Qingdao has become the leader of sailing development in the northern region. However, the high competitiveness of sailing driven by events was not conducive to the economic and cultural development of Qingdao. The existence of sailing sport was relatively expensive for ordinary sailing enthusiasts, and the training talent pool was weak and other negative factors. As one of the most complex recreational sports in the world, sailing could only be enjoyed by those who love life and practice it (Wang, 2007).

The aim of this paper was to explore the current development status of recreational sailing for the better development of leisure sports tourism in Qingdao, so as to promote the coordinated development of leisure sailing with society, economy and culture in Qingdao in the future.

\section{The Research Methods}

\subsection{The Bibliographic Method}

We had searched literatures through various media channels such as the Internet, and have done a lot of development research through the relevant books on the development of recreational sailing in Qingdao. It could provide strong theoretical foundation for the thesis writing, and we had hoped to find the deficiency of Qingdao in the development of recreational sailing on this basis of this article, and put forward corresponding Suggestions.

\subsection{The Expert Interview Method}

In this paper, we had interviews with Wei Liu who was the competition department of Qingdao yachting management center, Kejiang Xin who was the minister, and Sir Robin who was the British venture capital firm. We had consulted relevant experts to obtain relevant opinions in view of the difficulties and problems in the development of recreational sailboats in Qingdao city. Among them, 12 copies of expert questionnaires were issued, and 12 copies were recovered, with a recovery rate of $100 \%$ and an effective rate of $100 \%$.

\subsection{The Questionnaire Survey}

The research group randomly selected 500 citizens from Qingdao city for a questionnaire survey. Our main concern is the participation of sailing events, the understanding of recreational sailing and the development prospect of recreational sailing in Qingdao, etc.

This paper would analyzed the problems in the development of recreational sailing in Qingdao based on the survey results, and putted forward corresponding countermeasures and Suggestions according to the problems and public opinions. Among them, 500 questionnaires were issued and 500 were recovered, with a recovery rate of $100 \%$ and an effective rate of $100 \%$.

\section{The Overview of Recreational Sailing}

\subsection{The Definition of Sailing Sport}

\subsubsection{The Competitive Sailing (Wang, 2014)}

The competitive sailing was a professional sport dominated by competition. The participants usually have received professional training. They have used the rules the route selection and its refined operating techniques to win the race. Therefore, these athletes have needed a highly concentrated mind and a flexible analytical mind, which was not only a physical test but also a mental exercise.

So, the competitive sailing required higher training requirements for athletes, and environmental conditions and psychological quality training were the winning factors in the competition. Therefore, it was similar to many competitive sports, it was very difficult to popularize among the public. (Table 1)

Table 1. China's achievements in sailing at previous Olympic Games

\begin{tabular}{ccccc}
\hline Time(year) & Place & Athletes & Item & Results \\
\hline 1992 & Barcelona & Xiaodong Zhang & Women's windsurfing & Silver medal winner \\
1996 & Atlanta & Lishan Li & Women's windsurfing & Champion \\
2004 & Athens & Jian Yin & Women's windsurfing & Silver medal winner \\
2008 & Qing dao & Lijia Xu & Laser Radial & The bronze medal \\
2012 & Qing dao & Jian Yin & Women's windsurfing & Champion \\
\hline
\end{tabular}




\subsubsection{The Recreational Sailing}

Recreational sailing was related to the "leisure industry". It was a sport that could be popularized among the public. It was different from competitive sport: the recreational sailing had leisure boats and had a wide hull and a large space for human activities. Experiencers had not need to know the rules of sailing, and were in a relaxed state of body and minded to better experience the fun at sea.

The recreational sailing was a leisure activity that integrated entertainment, leisure, exploration and appreciation. Its safety coefficient was relatively high, which not only conformed to the traditional thinking of Chinese people, but also could lead more people to explore the unknown $70 \%$, and it was also another cornerstone of China's strategy of developing "maritime power".

\section{2 significance and Impact of Recreational Sailing Development (Cao, 2012)}

\subsubsection{The Culturally and Economically}

Sailing was not only a sport but also a culture. The constant development of sailing has created rich material wealth and economic wealth. It has driven the development of coastal economy and promoted the communication and cooperation with various cities and countries. China not only had a vast territory, but also had a vast coastline. Marine leisure culture was becoming a trend and demand of China in the future. Sailing industry was a complex industry that integrated tourism, sports, culture and exhibition.

In recent years, Qingdao has adhered to government guidance and market operation mode, encouraged enterprises and social forces to actively participate in and invested in the development of sailing sports that has meted the market demand, and Qingdao has also launched the "event + houseboat", sailing experience, sailing training, enterprise construction, customized projects and navigation education 6 overhaul leisure sports tourism products.

Qingdao sports industry gradually has formed the sailing industry system with diversified investment subjects, focusing on sailing manufacturing, sailing sports exhibition industry and sailing bodybuilding and leisure

Take the 2008 Olympic sailing race. The competition effectively had putted in motion the consumption demand of Qingdao, especially for the industries of construction, transportation, post and telecommunication, tourism and catering.

In 2008, for example, the permanent foreign population in Qingdao had increased from 156,000 to 220,000. Foreign tourists had grown to 1.4 million from 417,000, and the per capita GDP had promoted to 6,000 dollars from 2,829 dollars.

\subsubsection{Spiritual Culture}

Recreational sailing was different from competitive sport. It was a recreational sport that integrates the ornamental, recreational, recreational and exploratory nature of sailing.

It was a recreational sport that integrated the ornamental, recreational, recreational and exploratory nature of sailing boat. It became a carrier for sailing ships and ocean lovers. It had enriched people's leisure life and improves people's attitude towards life.

They had challenged themselves or relax themselves, which greatly had satisfied people's demand for freedom.

\section{The Development Status of Domestic and Foreign Recreational Sailing (Jing, 2017)}

\subsection{The Development Status of Foreign Countries}

Many nations had used the sea to carve out their own territories, such as Columbus's discovery of the new world and so on. Therefore, sailing in foreign countries had developed earlier.

Under the influence of national ideology, the popularity of sailing boats among the public was relatively fast. In many families this was not just a leisure activity, but a part of life. As well as fitness was a leisure sport for all ages.

According to incomplete statistics, there was one ship for every 22 people in Australia. The industry has generated $\$ 1.7$ billion a year. About 120,000 people were often involved in maritime sports, having used events to promote economic and cultural development.

In Sydney, sailing was the first choice for families. Many clubs were also scattered around Sydney harbors. In the summer, sailing enthusiasts could find their hobby to compete at any time. In addition to the games, there were various large and small children's camps and camps. Sailing has become an increasingly popular leisure activity. 


\subsection{The Domestic Development Status}

With the development of water sports, sailing in China has risen. It was only after the 2008 Olympics that sailing became known. Sailing enthusiasts were increasingly emerging, with great interest in sailing and the sailing has from the high income groups to ordinary citizens.

The number of sailing clubs in coastal cities, for example: Hainan, Xiamen, Shenzhen and Qingdao have been increasing. Many schools have developed specialized courses or societies related to navigation.

Sailing was very different in north and south China. The nautical movement was influenced by weather factors, and the cold air in autumn and winter has affected the sailing activities in the north, having made it the stasis of sailing boat development.

The south was less affected by weather. Both the training and tourism industries were developing relatively fast. Therefore, sports tourism brought by leisure sailing has become an important project in the development of coastal cities.

In recent years, the domestic yacht industry and tourism have developed to a large extent. Its operation mode was more abundant, the Consumers having been growing, the investment was also increasing. The development of recreational sailing in China and the world was getting better and better!

\subsection{The Analysis of Qingdao Recreational Sailing Development}

\subsubsection{The Policy Support of the State and Its Municipal Governments (Wu, 2018)}

1) Since 2006, the Qingdao municipal government has vigorously promoted "sailing on campus" and "welcome to sailing "series of activities. 27,000 teens have gone to sea training. There were more citizens participate in the sailing experience.

2) In 2009, the general office of Qingdao municipal party committee and the general office of the municipal government jointly had issued the opinions on accelerating the development of sailing. "The opinions" pointed out that we should give full play to the follow-up effect of the Olympic Games, having established a long-term mechanism for the development of sailing. We should let sailing get more extensive popularity in Qingdao, constantly improve the popularity and reputation in the world sailing sports field, and promote the good and rapid development of the whole city's economy and society.

3) General Administration of Sport of China and National development and reform commission nine departments, etc. "Water sports industry development plan" pointed out that the scale of water sports industry would reach 300 billion yuan by 2020 .

4) The Qingdao municipal government promulgated the 13th five-year plan for the development of sports. The plan called for continued progress in the construction of Qingdao's "capital of sailing". It has paid attention to the connotation of "the capital of sailing" city brand construction. We would launch extensive activities for young people to sail, actively introduced and build high-end sailing events, strengthen the physical education teacher and the sailboat coach's skill training, docked with "One Belt And One Road" national strategy, explored new routes.

5) At the end of 2015, the Qingdao municipal government issued the opinions on accelerating the reform and innovative development of Marine leisure tourism, witch has proposed to actively cultivate the emerging Marine leisure brand festival which can highlight the Marine advantages, urban characteristics and tourism characteristics. We would vigorously develop the specific requirements for such items as sailing boards, yachts, and motor boats, would create a unique Qingdao characteristics of the Marine leisure sports brand. So that the leisure sports tourism in Qingdao in a more standard market environment has been healthy development.

The government's support and promotion of sailing sport was a favorable assistant for the development of recreational sailing sport in Qingdao. Various related policies issued by the government have made sailing sport more recreational and popular. With the government's impetus, citizens were more likely to accept this sport. But in addition to popular policies, the laws and regulations related to recreational sailing are not very sound.

\subsubsection{The Recreational Sailing for the General Public}

After the Olympic sailing competition in Qingdao in 2008, Qingdao had been committed to developing sailing sport by relying on the effect of the sailing competition and regional coastal advantages, which were actively building a featured sports brand of "sailing capital set sail", vigorously, promoted the campus project of the Olympic project, and employed professional coaches to popularize sailing skills. 
In August 2017, the column groups of CCTV "One Belt and One Road" had gone to Qingdao Olympic sailing center to interview the municipal sailing popularization. As the core region of Qingdao "sailing city", it has actively integrated into the national strategy of "area". In the process of driving sailboat for universal, it has depth promoted the sailing with tourism, convention and exhibition, business and other integration development, and opened advantages more.

It has also got the most out of city of sailing; the sailing area characteristic has been promoted the development of Marine elements into the city and to the districts to build fashion in wider areas and at a deeper level. The goal of building a modern international city has played a good role in promoting the display and promotion of regional brands in cities.

China (Qingdao) international boat exhibition 2018 has allowed the public and tourists once again witness the splendor of the national rowing expo. We would build the Olympic sailing center into a high-end leisure tourist destination of Qingdao in summer. So that the sailing festival has become perfectly happy with the national fitness.

Therefore, sailing, sailing tourism has turned into people's public life, released sailing effective platform for the development of dividend. It also became a booster of leisure sports industry in Qingdao old kinetic energy conversion. It has dried business, tourism, culture and other related industry transformation and upgrading of important kinetic energy, and it has increasingly showed Qingdao more internationalized city image and beautiful CARDS.

In Qingdao city, the author randomly has selected 500 people about their understanding of recreational sailing and their participation in a simple questionnaire survey. See the Figure 1 and 2.

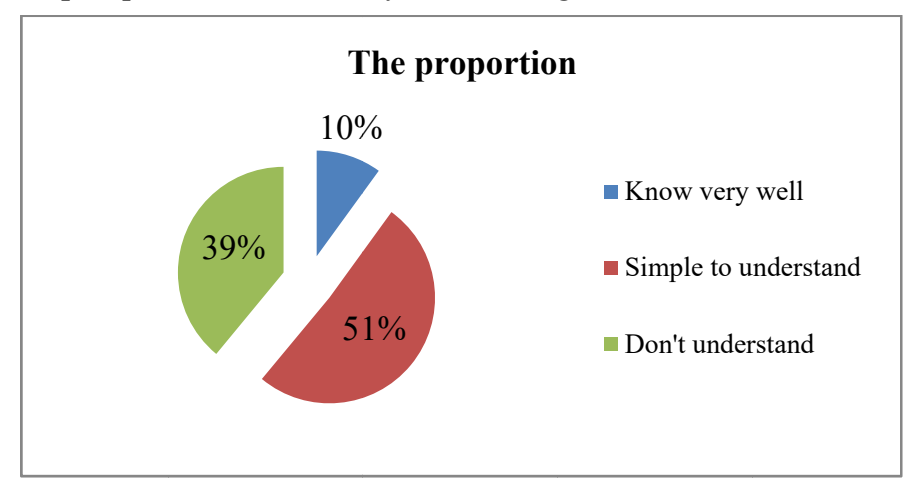

Figure 1. The people's understanding of recreational sailing

The statistics has showed that no more than half of people know about sailing, mostly through sailing events and online media. In the participation survey, 51 percent of the occasionally has involved people participated in three or more sailing experiences, but only 9 percent regularly participated.

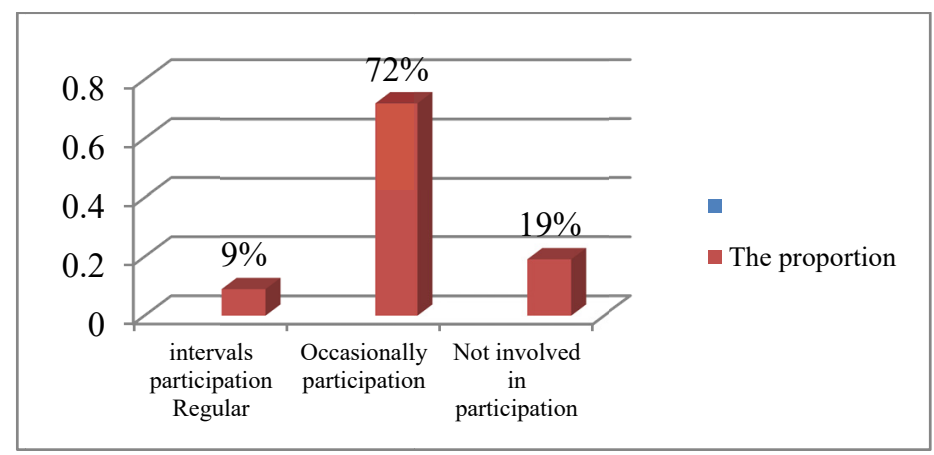

Figure 2. The mass participation in recreational sailing

According to reliable data analysis: the popularity of sailing in Qingdao was insufficient, some people had some misunderstandings on the understanding of the sailing, which was restricted by many other factors, and even local residents also had a little understanding. A lot of people had believed that sailing was a noble movement to it, there were also some people refused to understand the sport due to fear of water. Although there were a lot of activities related to sailing boats in Qingdao city, the public scope wad relatively small, which was not conducive to the popularization of sailing boats. 


\subsubsection{The Highlights of Sailing Events at All Levels in Qingdao}

In recent 20 years, Qingdao has held the sailing events mainly: it had successfully held the 2008 Beijing Olympic sailing events; Qingdao international sailing week and ocean festival, Qingdao limit sailing competition; Qingdao clipper sailing race; Qingdao Volvo global sailing competition; OP class sailing invitational; CCOR sailing; International youth sailing training camp and OP level international sailing invitational; Qingdao "mayor cup" junior and senior middle school students sailing competition has enriched and enriched the competitions of Qingdao, demonstrated the strong sailing strength and unlimited development potential of Qingdao, and demonstrated the unique charm of Qingdao as "sailing capital" and a famous international ocean city to the world.

\section{Conclusions and Recommendations}

The success of the Qingdao summit has also provided a good opportunity for the development of sports tourism and leisure sailing in Qingdao, and has enabled more people to understand and participate in the sport of leisure sailing to improve our quality of life and interest. We should do the following with the convening of this summit:

\section{1}

We should increase publicity and make use of various media channels to popularize sailing among the public, so as to highlight and expand the effects of the SCO summit on the development of leisure sports tourism in Qingdao (Jiang, 2010).

For example, the People's Daily, Xinhua News Agency, China central radio and television station and other media have focused on the great achievements of Qingdao's reform and opening-up in the past 40 years and the preparations for the summit, which have gave all-round, multi-lateral and multi-perspective publicity and published more than 10,000 original reports.

"One minute of Qingdao" was a promotional video has been launched by People's Daily. It has been viewed more than 80 million times. The promotional video "The combination of SCO" has over 200 million views on the Internet. The summit has become the best media to publicize Qingdao, which has greatly enhanced the visibility of the city (Su, 2017).

\section{2}

We should hold various tourism exhibitions well to enhance the influence of sailing tourism, and to increase the economic value of the tourism industry.

The SCO summit has made remarkable achievements in Qingdao's coastal building lighting project, municipal infrastructure renewal. At the same time, the air quality and urban environment quality has been improved. "Qingdao blue" has become the beautiful skyline of the Qingdao city.

According to the data statistics, the tourism industry of Qingdao has presented a good growth trend. In the first half of the 2018, the total number of tourist was about 39,026 , which was up $9 \%$ year on year. The total tourist consumption has reached 69.21 billion yuan, which was up 15 percent year-on-year. During "the May Day" holiday and "Dragon Boat Festival" holiday, the Qingdao has received 4.976 million tourists and 4.094 million tourists, which has achieved comprehensive tourism revenue of 7.32 billion yuan and 9.26 billion yuan.

The night scene lighting of the May 4th Square has made a new "the night tourism" hot. It has driven the development of accommodation, catering, leisure experience and other industries, and has greatly improved the quality and efficiency of Qingdao tourism (Zhang, 2016).

\section{3}

We should make long-term plans for tourism development after the summit (Andy, 2016)

(1) We should make contingency plans for evacuation and safety of tourists. Especially for the coastal line, the peripheral areas of the May 4th square and other key areas. We also should reasonably set up guide signs, warning signs and so on.

(2) We should do a good job in tracking, analyzing and predicting the number of tourists to Qingdao. We should establish an early warning mechanism and diversified information release channels to timely remind people gathering in key regions. So we could avoid risks caused by excessive influx of tourists.

(3) We should ensure orderly opening and scientific utilization of summit venues. For example, we could strengthen the function development of exhibition and festival. We also could avoid the conflict between different functions, and improve the comprehensive function of the venue. 
(4) We should appropriately extend the lighting performance time according to the tourism peak and the development demand of "night economy". We should strengthen the promotion of lighting works through the network platform, and should carry out activities such as night photography competition.

\section{4}

We should pay attention to the construction and management of Qingdao's characteristic culture.

After the summit, Qingdao should deeply explore the city's regional characteristics and cultural deposits and build the city brand, and further enhance international visibility and reputation $(\mathrm{Pu}, 2016)$.

\section{Subject Source}

This article is derived from the research on the development and countermeasures of sports tourism resources in Qingdao from the perspective of the "Shanghai cooperation summit", the planning project of Qingdao social science in 2018.

\section{References}

Andy, S. (2016). Blue water sailing. Contemporary sports technology, (2), 34-35.

Cao, L. (2012). The study on Confucian humanism and development strategy of sports culture industry in China. Qu fu normal university, 4.

Jiang, Q. J. (2010). The vicissitude of Marine tourism in China in recent years. Marine science, (11), 23-26.

Jing, X. Y. (2017). The analysis of current situation and development strategy of sailing and windsurfing. Contemporary sports technology, (7), 196-197.

Liu, Z. L. (2018). Seizing the opportunity to create a new development situation of "the capital of sailing ships". China Marine bulletin, (1), 17.

$\mathrm{Pu}, \mathrm{Y}$. F. (2016). The research on sailing sport culture and sailing sport development under the background of Chinese traditional navigation culture. Sociology of physical education, (6), 157-158.

Qing, D. (2018). Take the summit and start again- Qingdao continuously enlarges the summit effect to promote the high quality development review. Qingdao daily, (8), 31.

$\mathrm{Su}$, H. L. (2017). Extraordinary boats. The sports world, (5), 23-24.

Wang, W. C. (2014). The investigation and research on the status quo of sailing in China. Ocean university of China, 5.

Wang, X. C. (2007). The development of water sports tourism resources in Qingdao under the background of 2008 Olympic sailing competition. Beijing sports university, 6.

$\mathrm{Wu}$, X. S. (2018). The research on current situation and influencing factors of sailing in universities in Qingdao under the background of "sailing into campus activities". Shanghai normal university, 5.

Zhang, X. D. (2016). How to get 400,000 people to sail? - Qingdao has promoted fitness leisure industry development by sailing. People's political consultative conference, (11), 18.

\section{Copyrights}

Copyright for this article is retained by the author(s), with first publication rights granted to the journal.

This is an open-access article distributed under the terms and conditions of the Creative Commons Attribution license (http://creativecommons.org/licenses/by/4.0/). 